\section{región
sociedad}

Bracamonte Sierra, Alvaro; Lara Enríquez, Blanca E.; Borbón Almada, Martha I.

El desarrollo de la industria minera sonorense: el retorno a la producción de metales preciosos

Región y Sociedad, vol. VIII, núm. 13, enero-diciembre, 1997

El Colegio de Sonora

Hermosillo, México

Available in: http://www.redalyc.org/articulo.oa?id=10201302 


\title{
El desarrollo de la industria minera sonorense: el retorno a la producción de metales preciosos
}

\author{
Alvaro Bracamonte Sierra* \\ Blanca E. Lara Enriquez* \\ Martha I. Borbon Almada
}

Resumen: En este artículo muestra cómo la historia antigua y reciente del estado de Sonora se halla estrechamente ligada a la explotación de los ricos yacimientos mineros localizados en la entidad: a fines del siglo pasado, la economía sonorense se concentraba primordialmente en la extracción de metales preciosos, en especial el oro y la plata; después de las primeras décadas del presente siglo fueron los metales industriales, en particular el cobre, los que tomaron el liderazgo en este sector y, en consecuencia, del conjunto de actividad económica estatal. La importancia adquirida por la minería se desdibujó paulatinamente a causa de que la agricultura y la industria manufacturera ampliaron sus espacios de participa ción y consiguieron altas tasas de crecimiento.

* Investigador del Programa de Estudios Económicos y Demográficos de El Colegio de Sonora. Se le puede enviar correspondencia a El Colegio de Sonora, Obregón 54,Centro, Hermosillo, Sonora,tels. (62) 12-65-51 y 17-09-55, fax: 12-50-21, c. electrónico: abraca@ imparcial.com.mx

** Coordinadora de Investigación y Profesora Investigadora del Programa de Estudios Económicos y Demográficos de El Colegio de Sonora. Se le puede enviar correspondencia a El Colegio de Sonora, Obregón 54, Centro, HermosiIlo, Sonora, tels. (62) 12-65-51 y 17-09-55, fax:12-50-21, c. electrónico: blara@ imparcial.com.mx

*** Ayudante de investigación del Programa de Estudios Económicos y Demográ ficos de El Colegio de Sonora.Se le puede enviar correspondencia a El Colegio de Sonora,Obregón 54,Centro, Hermosillo, Sonora,tels. (62) 12-65-51 y 1709-55, fax:12-50-21. 
Sin embargo, el ensayo presenta las características que en la actualidad posee la industria minera, sobre todo en 1995 y 1996. Se observa un febril dinamismo en la exploración y explotación de varios metales que hace recordar sus mejores años. Lo diferente de este repunte, por una parte, es que los metales preciosos encabezan la expansión y, por otro lado, que el financiamiento de los nuevos proyectos es mayoritariamente la inversión extranjera. Una vez desarrollados estos puntos $s$ concluye que el nuevo boom de la minería sonorense se distingue por estar conformando una estructura de la producción minera donde lo que destaca es la tendencia menos nacional y más vulnerdble a los caprichos del ciclo económico internacional.

Abstract:This article shows the w ay in which ancient and recent history of the state of Sonora are closely linked to the exploitation of the states rich mining deposits. At the end of last century, Sonoran economy was mainly based on the extraction of precious metals, especially gold and silver; thereafter during the first decades of this century industrial metals, particularly copper, were the leaders in this sector and consequently, of the state's entire economic activity. The importance mining had acquired gradually decreased due to the fact that agriculture and manufacturing increased their participation, attaining high growth rates. Nonetheless, the essay shows the present characteristics of the mining industry and that which it has during the last year, mainly in 1995 and 1996. A feverish dynamism is observed in the exploration and exploitation of several metals, which remind us of the sector's best years. There is a difference in this new growth, since, on one hand, precious metals head the expansion and, on the other, financing of new projects is mainly throug foreign investment. Once these issues are developed, it is concluded that the new boom in Sonoran mining is different, since it comprises a mining production structure with a less national trend, that is more vulnerable to the whims of international economic cycles. 


\section{Introducción}

Las frecuentes noticias sobre la situación actual de la industria minera sonorense saturan las páginas económicas de los diarios regionales, dando cuenta de una vigorosa expansión. También los informes oficiales muestran la velocidad con la que la producción de metales preciosos se agrega a la de industriales, propiciando que Sonora escale los lugares de honor dentro de los principales estados de la república mexicana. Tal parece que el reciente boom ha tomado por sorpresa a una franja importante de la sociedad que desconocía nuestra rica historia minera y las grandes posibilidades de multiplicar los volúmenes de producción, pues Sonora es parte de un macizo geológico abundante en metales Las recientes exploraciones y explotaciones de los minerales únicamente ponen al día el proverbial y tradicional prestigio minero sonorense. Este ensayo tiene el objetivo de mostrar las diferentes etapas por las que ha pasado el desarrollo de la industria minera sonorense, para finalizar con las características que la minería de los noventa presenta en el actual boom.

El artículo se compone de cuatro apartados. El primero tiene el objetivo de presentar los antecedentes históricos de la minería sonorense, desde las exploraciones de los aventureros que acompañaban a los misioneros jesuitas, hasta el regio desarrollo alcanzado durante las tres primeras décadas del presente siglo.

En el segundo apartado, analizamos las causas que dieron origen al retraimiento de la otrora pujante industria minera. Señalamos que la mexicanización fue la respuesta a la de dinamismo, que posteriormente condujo a una asombrosa mejoría de la producción en la década de los ochenta. La recuperación se describe en la tercera parte, donde se confirma, mediante diferentes variables bá sicas, la importancia que adquiere la minería en el periodo 1970-1990.

En la siguiente parte, se plantean las nuevas características que asume la industria extractiva: la producción de metales preciosos 
es el dato diferente y se destaca además, que este crecimiento descansa en la inversión foránea y se destina al mercado externo. Se ofrecen estadísticas que aclaran los rasgos de la nueva minería.

Por último, en las conclusiones se hace una breve reflexión respecto al tipo de modelo de desarrollo que en la actualidad se fomenta.

\section{Antecedentes históricos de la minería}

La historia de la colonización puede considerarse, en términos gruesos, como la historia de los pueblos fundados al abrigo de la explotación de abundantes minerales situados en el norte de la Nueva España. Zacatecas, San Luis Potosí y Durango son algunas de las localidades erigidas en la ruta del oro descrita por Alvar $\mathrm{Nu}$ ñez Cabeza de Vaca. La febril e insaciable sed de metales preciosos imprimió el sello característico del empuje colonizador de los españoles. Donde se detectaba una veta se conformaba un centro de población cuya dinámica económica giraba en torno a la extracción de oro y plata.

La historia del estado de Sonora no es distinta. Las misiones jesuitas fueron los primeros asentamientos de esta parte de la Nueva España; la labor evangelizadora de la Compañía de Jesús se practicaba a través de la enseñanza de la agricultura y ganadería; sin embargo, el crecimiento de esas villas fue favorecido por la exploración y producción de metales preciosos, constituyéndose, desde entonces hasta las primeras décadas de este siglo, en el eje rector de la economía sonorense. Alamos es el ejemplo clásico del origen y florecimiento de los pueblos coloniales al amparo de la actividad minera.

Sin embargo, la inestabilidad de los mercados que distinguió la última parte del siglo XIX tuvo consecuencias interesantes. LoS precios del oro y la plata cayeron en $\mathbf{2} \%$ anual en el porfiriato, afectando severamente los centros mineros establecidos con capitales extranjeros: en 1905 la actividad minera de Alamos, que era 
la principal concentración poblacional de la época, quedó reducida a cinco minas. ${ }^{1}$

No obstante, la minería sonorense, lejos de desaparecer, vio fortalecida su presencia; para ello se modificaron sustancialmente los metales extraidos y adquirieron así una influencia determinante en el desarrollo económico del estado. En tales circunstancias, la pregunta obligada es: ¿En qué consistió esa reorientación que permitió situar a la industria extractiva en el corazón de la economía? La coincidencia de un conjunto de factores condujo a la minería de metales industriales a ocupar el lugar que anteriormente tenían los metales preciosos. Un elemento explicativo del desplazamiento fue la volatilidad de los mercados que provocó dificultades para mantener una economía sustentada en la producción de mercancías cuyos precios caían de manera sostenida. Al mismo tiempo, en 1890 la industrialización del mundo occidental había madurado, incrementándose la demanda de materias primas, como sucedió con los minerales que requería la expansión de las industrias side rúrgica y eléctrica. Con el aumento de la demanda de los metales industriales se elevaron los precios, y se volvió atractiva y rentable su producción.

En estas condiciones, el estado de Sonora registró una acelerada expansión: de 1880 a 1910, la población prácticamente se duplicó, esto es, se incrementó en $91 \%$ (tal como se aprecia en la gráfica 1). El suceso no se explica exclusivamente por el crecimiento natural, sino también por las migraciones estimuladas por el desarrollo minero de la zona serrana del noreste de la entidad. ${ }^{2}$

Sin duda, el inversionista y aventurero William C. Green nunca imaginó que la "4c" (Cananea Consolidated Copper Company) se convertiría en el detonador de la economía regional. La extracción de cobre posibilitó que rancherías levantadas en las cercanías de

1 Las minas extranjeras que pudieron resistir son: La Quintera en el Municipio de Aduana, con un total de $\mathbf{2 1 0}$ trabajadores; La Zambona en el Municipio de Minas Nueva con 100 hombres empleados; La Gloria con 150 trabajadores; La Prieta de San Miguel con 175 trabajadores y Guadalupe, con 100 obreros, en el Municipio de Río Chico;Juan José Gracida Romo (1985), p. 90. 


\section{Gráfica 1}

\section{Crecimiento de la población \\ Sonora 1880-1910}

Fuente: Elaboración propia con base en datos tomado de Historia General de Sonora, Gobierno del Estado de Sonora, tomo IV, p. 29, Hermosillo, 1985.

los yacimientos minerales se transformaran en poco tiempo en centros de intensa actividad económica ( tal como se advirtió en los distritos de Moctezuma y Arizpe). Cananea, situada en este último distrito, contaba en 1891 con 100 habitantes y para 1900 la población ascendía a cerca de 900 . Gracias al surgimiento del emporio de Green, el antes marginado pueblo de Cananea registró en 1905 más de 20 mil habitantes, se convirtió así en la ciudad más populosa e importante durante los primeros años del presente siglo.

No sólo Cananea se benefició de la fiebre despertada por el metal rojo; la economía y la población del distrito de Moctezuma 
presentó en ese tiempo un crecimiento notable. ${ }^{3}$ Las minas situadas en Nacozari y Pilares, pertenecientes a La Moctezuma Cooper Co., observaron un destacado incremento en el beneficio de cobre; tan sólo en Pilares llegaron a laborar 2,000 trabajadores. 4

Las tres ciudades conformaron la base de la estructura económica sonorense en los umbrales del siglo XX. La minería - no sin altibajos - fue la fuente principal de donde emanaba la prosperidad y la riqueza de Sonora. 5

Sostener que la economía descansó, en las décadas iniciales del presente siglo, en la producción minera y ganadera, no significa que el comercio, la agricultura y otras actividades no estuvieran presentes 0 no fueran importantes, sino queremos decir que la minería junto con el sector ganadero formaban el centro de la estructura económica, que ligaba - 0 de ellas dependían- a las demás actividades mercantilizadas. ${ }^{6}$

Este auge minero finalizó con la crisis mundial de 1929-1932 ya que de ésta se derivaron reducciones en el mercado de exportación así como en los precios del cobre, desarticulando el tejido económico levantado a su alrededor. La crisis afectó principalmente a la minería y pronto tocó el resto de la estructura productiva provocando una profunda recesión económica, puesto que el sector minero y ganadero poseían una producción altamente comercializable e integrada al aparato de servicios financieros y comerciales. Esta estrecha vinculación confirmó por qué con la caída de los precios internacionales del cobre, entre 1930 y 1932, quebraron también

Entre 1900 y 1910 el crecimiento demográfico es impresionante: pasa de 17,606 a 28,015 habitantes.

4 Juan José Gracida Romo (1985), p. 95,

5 En este periodo, la economía se desarrollaba a través de enclaves. En 1905, se contaba en la entidad con 122 minas que producían poco más de 1,279 millones de kg de cobre, oro y plata. El valor aproximado de esta producción ascendió a $\mathbf{2 4 . 5}$ millones de pesos y las exportaciones alcanzaron los $13.5 \mathrm{mi}$ llones, Juan José Gracida Romo (1985), p. 91. José Carlos Ramírez (1991), p. 43. 
el comercio y los servicios en los centros de acopio de los fundos mineros y ganaderos. ${ }^{7}$

Al resquebrajarse el complejo minero, el gobierno se vió obliga do a aplicar medidas emergentes que atenuaran los estragos de la recesión, sin embargo, los apoyos oficiales fueron insuficientes para hacer renacer el poderío minero anterior a 1930. Los incrementos ocasionales de la producción no tuvieron el arrastre de la época de mayor esplendor; algo había cambiado, ya no era posible depender el funcionamiento económico de una actividad subordinada a los ciclos impredecibles de la economía mundial. El sector minero había sido desplazado de su papel protagónico, y se iniciaba un periodo que se extendería por más de 30 años, durante el cual su desempeño no tuvo el vigor de antaño y la agricultura se convirtió en el centro de gravitación de la economía.8

\section{Comportamiento de la minería durante 1940-1970}

"El estado de Sonora fue una de aquellas regiones mineras que vivieron la segunda guerra mundial bajo la buena estrella del auge exportador, beneficiándose del enorme incremento en el consumo de metales y minerales generado por la demanda bélica. Las grandes minas de cobre de Cananea y Nacozari reactivaron sus añejos socavones para responder a una demanda ilimitada". 9

El papel que jugó la minería en la trama económica se advierte al considerar los ingresos fiscales que en términos reales cayeron en el lapso de 10 años; también se observó una declinación de la liquidez del orden bancario y comercial.Como culminación de la crisis,el Banco de Sonora cerró. José Carlos Ramírez (1991), pp. 97-123.

8 Gobierno del Estado de Sonora (1985), pp. 97-123.

9 Oscar Contreras Montellano y Miguel Ángel Ramírez (1988), p. 243. 
El aumento en las compras de materias primas implicó un proceso de modernización tecnológica y la ampliación de las instalaciones mineras auspiciada por el gobierno de Estados Unidos. El programa fue especialmente aprovechado por la 4c en Cananea, perteneciente en ese entonces, a la Anaconda Copper Company para, entre otras cosas, abrir por primera vez a la explotación un tajo a cielo abierto. 10

Se iniciaba así una nueva etapa en la minería sonorense concentrada en aquel momento en la producción generada por Cananea, misma que mostraría una particular fortaleza para sortear los difíciles años de la posguerra. Efectivamente, el auge minero duró el tiempo de guerra;después, las condiciones que permitieron su recuperación se modificaron notablemente, dando inicio a un largo periodo de invernación donde esta industria fue una pálida sombra del brío de sus años de mayor apogeo.

Las causas de la caída no se reducen a la disminución en la demanda de metales, sino que incluyen modificaciones en la natura leza de los flujos de inversión extranjera (IE); esto es, el retraimiento de la IE en áreas relacionadas con los recursos naturales, se origina con el gobierno cardenista pues pone en marcha una política naciona lista para rescatar dichos recursos. ${ }^{11}$

El enclave minero sonorense, como todos los de su tipo, dependía excesivamente de la IE, que al suspenderse provocó su declinación. Mientras tanto, en el interior del país se advertía una compulsión industrializadora que influiría en todas las actividades productivas. La industrialización promovida por el Estado aceleró la demanda interna de algunos minerales industriales propiciando un proceso de integración de los antiguos enclaves al mercado interno que, complementado con una agresiva política oficial de control de los recursos naturales, pusieron las condiciones para la formidable expansión, posterior a los sesenta, de la planta productiva minera.

La culminación del largo proceso se produjo en 1961 cuando el gobierno mexicano promulgó la Ley Reglamentaria del Artículo

10 Oscar Contreras Montellano y Miguel Ángel Ramírez (1988),pp. 243-245.

11 Sin duda,esto fue un reflejo de los resultados de la revolución de 1910. 
127 Constitucional en Materia de Explotación y Aprovechamiento de los Recursos Minerales, más conocida como "Ley de Mexicanización de la Minería". Lo destacable fue el marco de restricciones impuestas al capital extranjero para invertir en la industria minera. De manera complementaria, se facultó al Estado para emprender directa o por conducto de firmas privadas, labores de exploración y explotación. 12

La mexicanización inició un periodo de intensos cambios tanto en la producción como en la estructura de la propiedad, proceso que fue finiquitado con la adquisición en 1971 de la 4c, y con la formulación de un ambicioso programa de inversiones que modernizó la estropeada planta productiva minera. ${ }^{13}$

\section{Los indicadores del crecimiento entre 1970-1990}

Producto de las condiciones antes descritas se observó una reactivación de la minería a tal grado que, desde finales de los años sesenta, una larga lista de empresas comenzaron trabajos de exploración, construcción, explotación y beneficio con un vigor que quizá sólo es comparable con el de los primeros treinta años del siglo. Destacan por su magnitud las ampliaciones emprendidas por la Compañía Minera de Cananea y el inicio de operaciones de las siguientes empresas: Compañía Minera de Cobre S.A., en La Caridad (municipio de Nacozari); la Compañía Minera Lampazos S.A. de C.V. en Lampazos (municipio de Tepache); la Compañía Minera de Cumbobabi, S.A. de C.V. en Cumpas;La Compañía Minera La Negra y Anexas, S.A. de C.A. en San Bernardo (municipio de Alamos) y la empresa Barita de Sonora, S.A.en Mátape (Villa Pesquei ra). Junto a estas seis grandes empresas, por lo menos otras 20 de 
menor tamaño emprendieron operaciones, acumulando una inversión cercana a los $35 \mathrm{mil}$ millones de pesos a precios de 1980.14

El impacto de los nuevos centros mineros sobre los indicadores básicos de la minería sonorense no podía ser más impresionante: entre 1970 y 1990, el volumen de producción de los principales productos mineros se incrementó en $400 \%$, pasando de $112.6 \mathrm{mil}$ a $\mathbf{5 7 3 . 5}$ mil toneladas (ver gráfica 2), pero si la comparamos con la producción de 1961 el incremento es superior a 1,600\%. En el mismo lapso, el valor de la producción pasó de 716 mil nuevos pesos a poco más de dos millones de nuevos pesos (ver gráfica 3), lo que a precios constantes de 1980 , significa un incremento de $310 \%$.

Para ilustrar el desempeño de la minería en este periodo es necesario dar cuenta de dos indicadores que documentan el poderoso empuje registrado entre 1970 y 1990,la participación de la minería en el Producto Interno Bruto Estatal (PIBE) pasó de $4.6 \%$ a 8.7\% (ver gráfica 4).Asimismo, la fuerza de trabajo ocupada en la minería aumentó de 4,266 en 1970 a 13,486 en 1990 (ver gráfica 5).

Los datos anteriores confirman la recuperación de la actividad en la estructura económica regional, pues presenta un ritmo de crecimiento por encima de la economía en su conjunto. En especial resulta revelador el contraste si lo comparamos con la evolución del sector agropecuario: mientras que entre 1970 y 1990 la minería ganó cuatro puntos porcentuales en la composición del PIBE, la agricultura y la ganadería perdieron alrededor de 13 puntos, pasando de $29 \%$ en 1970 a $16 \%$ en 1990 (ver gráficas 6 y 7). dores económicos. Así, de las 82 firmas mineras registradas por el gobierno estatal en 1984, las seis "grandes" concentraban más de $97 \%$ de la capacidad instalada en las plantas de beneficio;generaban la totalidad del cobre, molibdeno y barita; $\mathbf{8 0} \%$ del oro, plata, plomo y zinc producidos en Sonora. Por otro lado, las dos grandes empresas cupríferas poseen la mayor proporción del volumen de producción del país, con $\mathbf{8 4 \%}$ del total. Oscar Contreras Montellano (1986), pp. 263-264. 


\section{Gráfica 2 \\ Volumen de la producción \\ de los principales productos mineros. Sonora 1970-1990}

Fuente: Para 1970, INEGI (1984), M anual de Estadísticas Báścas de Estado de Sonora, para 1990, Gobierno del Estado de Sonora, Secretaría de Desarrollo Económico y Productividad, Dirección de Fomento Minero. 


\section{Gráfica 3}

Valor de la producción de los principales metales.

Sonora 1970-1990

Fuente: Para 1970, INEGI (1984), M anual de Estadísticas Básicas del Estado de Sonora, para 1990, Gobierno del Estado de Sonora, Secretaría de Desarrollo Económico y Productividad,Dirección de Fomento Minero. 


\section{Gráfica 4}

\section{Participación de la minería en el}

Producto Interno Bruto estatal. Sonora 1970 y 1990

Fuente: Para 1970, INEGI (1984), M anual de Estadísticas Básicas del Estado de Sonora, para 1990, Banco de datos económicos. 


\section{Gráfica 5}

\section{Número de trabajadores empleados en la minería.}

Sonora 1970 y 1990

Fuente: INEGI (1984), M anual de Estadísticas Básicas del Estado de Sonora. Gobierno del Estado de Sonora, Secretaría de Desarrollo Económico y Productividad, Dirección de Fomento Minero. 


\section{Gráfica 6}

Producto Interno Bruto, participación porcentual Sonora 1970

Fuente: INEGI (1984), M anual de Estadísticas Básicas del Estado de Sonora.

\section{Gráfica 7}

\section{Producto Interno Bruto estatal, participación porcentual Sonora 1990}


La combinación del proceso de reestructuración iniciado con la "Ley de Mexicanización" y las favorables condiciones externas, permitieron el repunte de la minería; entre estas últimas destacan las dificultades que, desde los años cincuenta, enfrentan los Estados Unidos para satisfacer la demanda interna de metales industriales, primordialmente el cobre. La industria cuprífera estadounidense tiene desde entonces una serie de problemas estructurales que impiden conservar su tradicional liderazgo en esa materia. Estos obstáculos se agudizaron visiblemente a partir de los años setenta que marcan una franca tendencia al agotamiento de sus yacimientos; resaltan también los altos costos energéticos de la explotación de minerales de baja ley, las estrictas normas ecológicas así como la elevación de los salarios. ${ }^{15}$ Estos factores y la reforma económica nacional emprendida desde mediados de la década anterior sentaron las bases para el nuevo desarrollo minero de los años noventa.

En efecto, la economía mexicana empezó en ese entonces una transformación estructural exigida por el agotamiento del modelo de industrialización vigente. La modernización abarcó la privatización de la empresas paraestatales, la apertura comercial y una radical desregulación que motivó los cambios en la Ley de IE promulgada desde 1973.16 Todo ello produjo una acelerada transformación de la economía mexicana donde la minería fue incluida.

Durante la administración de Carlos Salinas de Gortari se puso en marcha el "Proyecto de Reestructuración del Sector Minero" cuyo objetivo esencial era la liberalización de la industria. Bajo esta lógica, se modernizó la legislación que abarcó modificaciones rrigió la delicada ambigüedad y discrecionalidad que ese marco normativo tenía sobre la inversión foránea. Con ello, el grado de apertura de la economía mexicana se amplió considerablemente: pasa de $33 \%$ contemplado en la Ley de 1973 , a $73 \%$ con la reglamentación de 1989 . Posteriormente, con la nueva Ley de Inversiones Extranjeras prácticamente todos los sectores estarían abiertos a la inversión foránea, ampliándose el grado de apertura a 81.4 \%. Es importante señalar que con esta ley se da trato nacional a la inversión de origen externo. 
sustanciales en el Artículo 27 Constitucional y una nueva Ley fiscal. 17

Por otro lado, las mejoras en la tecnología concretadas durante el periodo, hicieron rentables yacimientos minerales de baja ley a la vez que permitieron abatir los costos Estos avances se extendieron a la fase de exploración, cuyos resultados se volvieron más confiables y precisos. ${ }^{18}$ En tales circunstancias era de esperarse un nuevo impulso en la inversión minera para dar origen a una fase distinta en el desarrollo de la industria extractiva sonorense.

\section{La minería sonorense en los noventa: la nueva historia de una antigua industria}

Cuando parecía que la minería había concluido su ciclo de expansión e iniciaba una etapa de madurez y consolidación, en los años recientes se viene observando un nuevo ímpetu en la extracción de minerales. El inesperado auge es diferente al producido en los setenta y ochenta, cuando bajo el velo protector del Estado se consolidó un complejo minero de talla mundial, concentrado principalmente en el metal rojo; es distinto también al crecimiento que

17 Este conjunto de disposiciones permite la liberalización de sustancias y zonas mineras anteriormente reservadas para uso exclusivo del Estado; amplían de tres a seis años las concesiones de exploración y de $\mathbf{2 5}$ a 50 años las de explotación, prorrogables hasta por otros 50 años; se permite con la nueva ley de inversiones extranjeras hasta el $100 \%$ de participación de capital foráneo; se dan garantías de continuidad en la política minera.Con la reforma al 27 constitucional,se otorga libertad al ejidatario de vender sus tierras a inversionistas particulares. El reglamento en materia minera expedido en 1990, simplificó los trámites y proporcionó seguridad jurídica a fin de estimular inversiones de largo plazo, se estableció un procedimiento único para la recepción,despacho y resolución de $70 \%$ de los asuntos mineros. La nueva ley fiscal eliminó los impuestos sobre la producción,exportación de minerales y de dividendos; redujo los impuestos a la importación de maquinaria, de la renta del beneficio neto de las compañías, renta de personas físicas,el IVA, etcétera. Karin Trabecke Z.,(1996), p. 12.

18 Con ello se produjo una proliferación de empresas especializadas en servicios experimentales de procesos metalúrgicos y análisis químicos. 
se registró en las primeras décadas de este siglo. El actual apogeo se parece más a la minería que prosperó en el siglo pasado, especializada en la explotación de metales preciosos, propiedad de inversionistas extranjeros y cuya producción estaba destinada al mercado externo.

En los últimos seis años, se han instalado en la geografía sonorense, sea para la fase de exploración, explotación o en servicios complementarios, alrededor de 51 empresas ${ }^{19}$ que en conjunto acumulan entre 1990-1996, una inversión de 17 millones de pesos, donde el incremento porcentual anual de los últimos dos años supera el $\mathbf{2 0 0 . 0 \%}$ lo que significa una tasa de crecimiento de $19.6 \%$ a precios de 1980 . (ver cuadro 1 ).

\section{Cuadro 1}

Evolución de la inversión extranjera directa y de la inversión minera. Sonora 1990-1996

(miles de pesos de 1980) 
En este monto de inversión, predomina la participación del ca pital foráneo. De las firmas establecidas en los últimos años 46 pertenecen a empresarios extranjeros que operan en las fases de explotación, exploración o servicios complementarios. La inversión acumulada por estas empresas de 1990 a 1994 asciende a 59.9 millones de dólares, sobresalen los años de 1993 y 1994 donde la inversión extranjera alcanza un monto de 56.5 millones de dólares que representa $94.3 \%$ de la inversión total acumulada en esos años por el sector (ver cuadro 2).

Destacan por su magnitud la inversión efectuada por Minera He cla S.A.de C.V. de Estados Unidos en su mina La Choya; Oro de Sotula S.A. de C.V. de Canadá en la mina Santa Gertrudis, del municipio de Cucurpe, Exploraciones El Dorado S.A.de C.V. de Canadá en La Colorada; Geomaque S.A. de C.V. de Canadá; Lluvia de Oro S.A. de C.V. de Canadá y Minera Roja S.A. de C.V. de Australia; todas en la explotación de oro. En molibdeno está Molimex SA. deC.V. de Chile. En proyectos de exploración se encuentra Minera Nyco S.A de C.V. subsidiaria de Fording Coal LTD, que inició la construcción de su mina Pilares al noroeste de Hermosillo, produciendo wallastonita. Además, existen proyectos de ampliación de Mexicana del Cobre S.A de C.V., Mexicana de Cananea, Minera María S.A de C.V., Minera San Augusto S.A. subsidiaria de Placer Dome Inc. de Canadá en Mulatos, Exploraciones Peñoles S.A. en coinversión con Newmont Mining Co. de Estados Unidos con el proyecto La Herradura en Caborca. En conjunto, se estima una derrama en cuanto a inversión para los próximos años de 585 millones de dólares 20

Las repercusiones del acelerado crecimiento sobre algunos indicadores económicos de la industria extractiva son apreciables. Entre 1991 y 1996, el volumen de la producción de los principales productos mineros se incrementó en $85 \%$ aproximadamente.

38 son de exploración, 49 ofrecen servicios, 11 son laboratorios y tres son de explosivos Gobierno del Estado de Sonora,Sedepro, Dirección General de Fomento Minero, (1997), Directorio Minero, abril. 
Sobresalen los incrementos de $900 \%$ en el oro ${ }^{21}$ y arriba de $300 \%$ registrado por el molibdeno 22 (ver gráficas 8,9 y 10).

\section{Gráfica 8}

\section{Volumen de la producción de oro \\ Sonora 1991-1996}

Fuente: Gobierno del Estado de Sonora, Secretaría de Desarrollo Económico y Productividad, Dirección de Fomento Minero; para el año de 1996 se utilizó información del suplemento del periódico Cambio, p. 12, mayo de 1997.

21 De 842 kilogramos en 1991 a 8651 en 1996.

22 En 1996, se produjeron 11,783 toneladas cuando en 1991 se obtuvieron 2 842. 


\section{Gráfica 9 \\ Volumen de la producción de molibdeno \\ Sonora 1991-1996}

Fuente: Gobierno del Estado de Sonora, Secretaría de Desarrollo Económico y Productividad, Dirección de Fomento Minero; para el año de 1996 se utilizó información del suplemento del periódico Cambio, p. 12, mayo de 1997.

\section{Gráfica 10}

\section{Volumen de la producción de cobre}

Sonora 1991-1996

Fuente: Gobierno del Estado de Sonora, Secretaría de Desarrollo Económico y Productividad, Dirección de Fomento Minero; para el año de 1996 se utilizó información del suplemento del periódico Cambio, p. 12, mayo de 1997. 
De manera similar, el valor de la producción total varió sensiblemente: de poco más de 1.86 billones de nuevos pesos en 1992 pasó a 7.2 billones en 1996 (ver gráfica 11), que estimados a precios constantes de 1980 representan un aumento de $65.6 \%$.

\section{Gráfica 11}

\section{Valor de la producción minera total \\ Sonora 1992-1996}

Fuente: Gobierno del Estado de Sonora, Secretaría de Desarrollo Económico y Productividad, Dirección de Fomento Minero; para el año de 1996 se utilizó información del suplemento del periódico Cambio, p. 12, mayo de 1997.

Una característica del actual boom minero es la pérdida de importancia del cobre en la composición del valor total de la industria. Efectivamente, la minería de la entidad ha dejado de ser monoproductora para diversificar el número de metales que se extraen del subsuelo sonorense. Con la diversificación, el cobre ha disminuido su participación en lo que va de la década. En 1990, el cobre concentraba $90 \%$ del valor total de la producción, actualmente el oro y el molibdeno han adquirido tal importancia,que entre 1990 
y 1996 el primero aumentó nueve puntos, al pasar de 2.0 a $11.1 \%$, y el molibdeno pasó de $1.6 \%$ a $5.9 \%$ en 1996 . (ver gráficas 12,13 y 14).

\section{Gráfica 12}

Peso relativo del valor de la producción de oro en el total de la producción minera. Sonora 1990-1996

Fuente: Gobierno del Estado de Sonora, Secretaría de Desarrollo Económico y Productividad, Dirección de Fomento Minero; para el año de 1996 se utilizó información del suplemento del periódico Cambio, p. 12, mayo de 1997. 


\section{Gráfica 13}

\section{Participación relativa del valor de la producción de cobre} en el valor total de la producción minera Sonora 1990-1996

Fuente: Gobierno del Estado de Sonora, Secretaría de Desarrollo Económico y Productividad, Dirección de Fomento Minero; para el año de 1996 se utilizó información del suplemento del periódico Cambio, p. 12, mayo de 1997. 


\section{Gráfica 14}

Participación relativa del valor de la producción

de molibdeno en el total de la producción minera

Sonora 1990-1996

Fuente: Gobierno del Estado de Sonora, Secretaría de Desarrollo Económico y Productividad, Dirección de Fomento Minero; para el año de 1996 se utilizó información del suplemento del periódico Cambio, p. 12, mayo de 1997.

Una expresión del significativo crecimiento minero es el avance de Sonora en la producción nacional: en 1980, el estado participó con el $12 \%$ del valor generado por toda la industria minera mexicana; en 1994, aportó $24 \%$ y desde 1995 ocupa el primer sitio con una aportación que oscila alrededor de $32 \%$ (ver cuadro 3).Además en 1997, la entidad es líder nacional en la producción de cinco minerales, tres metálicos y dos no metálicos. Entre los primeros se encuentra oro, cobre y molibdeno y, en segundo, gra fito y barita. 23 
REGIÓN Y SOCIEDAD / VOL.VIII / NO. 13-14. 1997

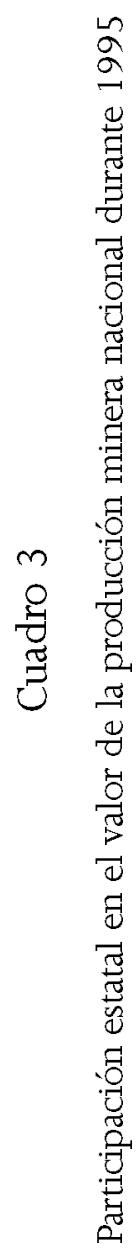


Para una mayor comprensión de los alcances de los datos anteriores es importante mostrar dos indicadores que revelan el impacto provocado por el dinamismo actual de la minería. Entre 1992 y 1995, la participación de la industria extractiva en el PIBE cambió de $8.06 \%$ obtenido en el primer año a 9.10 alcanzado en el segundo (ver cuadro 4). El resultado muestra la vigorosa evolución de la actividad y confirma, al mismo tiempo, un ritmo de crecimiento mayor al registrado por la economía en su conjunto, esto es, el PIBE creció $1.6 \%$ en promedio anual en ese periodo, mientras que la industria minera lo hizo a una tasa superior al $6 \%$ en promedio anual para esos años (ver cuadro 5).

La minería fue de las actividades que más crecimiento registra en los últimos años (ver cuadro 5), incrementando así su participación en la composición del PIBE: de 1992 a 1995 el PIB minero pasa de $8.1 \%$ a $9.1 \%$, confirmando el buen desempeño respecto a otras actividades. Dicha tendencia es atípica sobre todo si revisamos la trayectoria del sector agropecuario, que continúa cayendo de manera irreversible.

Por otra parte, la minería ha jugado un papel relevante en la orientación exportadora de la economía regional. Entre 1992 y 1995, las exportaciones mineras se incrementaron explosivamente, crecieron más de $\mathbf{1 4 0 \%}$, al pasar de 217 millones de dólares a 535 millones de dólares (ver gráfica 15). En cambio, las exportaciones totales del estado crecieron sólo 77\% (de 2987 millones de dólares en el primer año a 5292 en 1995) (ver gráfica 16), es decir un aumento inferior a $26 \%$ en promedio anual. Las exporta ciones mineras incrementaron su participación en la estructura porcentual de las exportaciones totales, en 1995 colaboraron con $8.35 \%$ y apenas tres años antes lo hicieron con $1.71 \%$, (ver gráfica 17 ). 


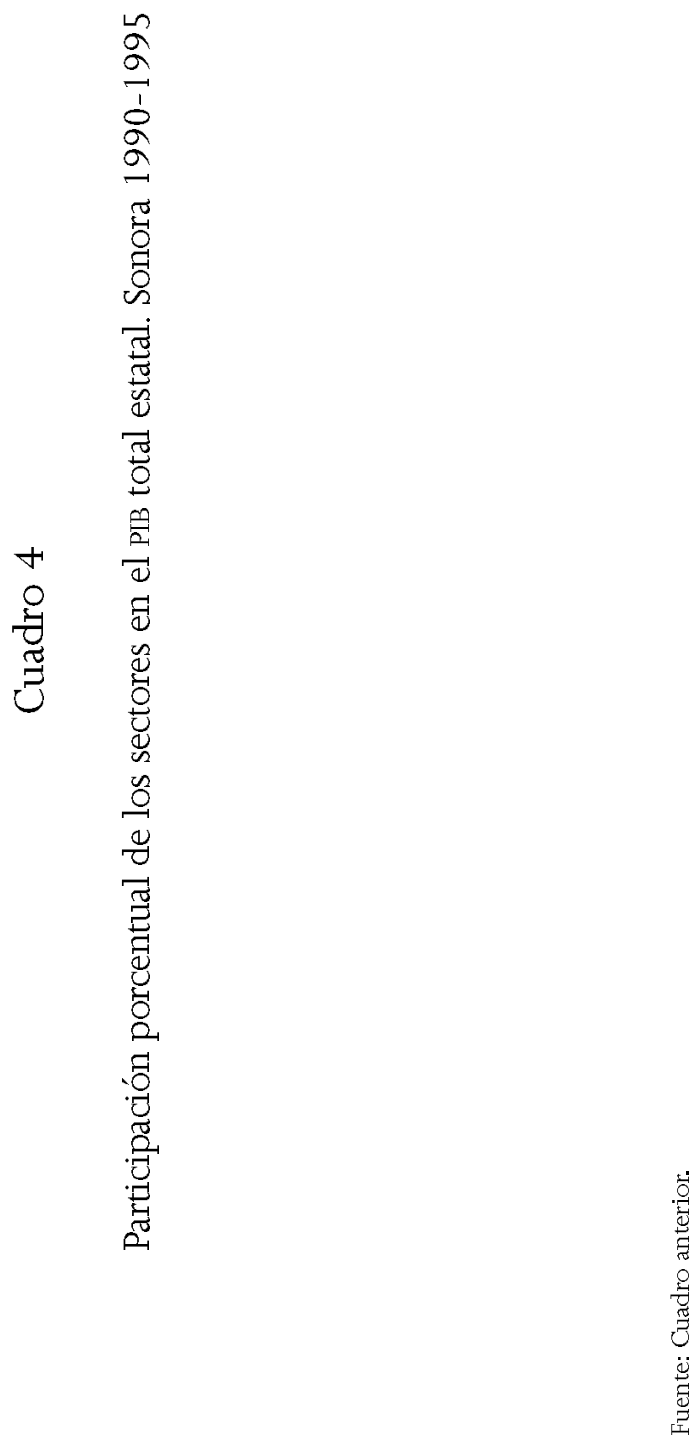


REGIÓN Y SOCIEDAD / VOL. VIII / NO. 13-14.1997

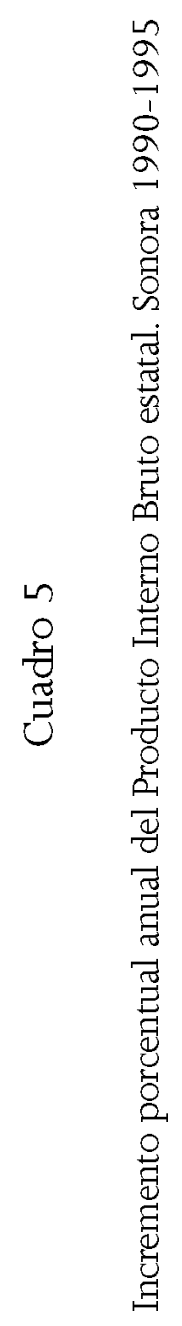




\section{Gráfica 15}

Valor de las exportaciones mineras. Sonora 1992-1996

Fuente: Gobierno del Estado de Sonora, Secretaría de Desarrollo Económico y Productividad,Dirección de Fomento Minero.

\section{Gráfica 16}

Exportaciones totales. Sonora 1992-1995

Fuente: Gobierno del Estado de Sonora, Secretaría de Desarrollo Económico y Productividad, Dirección de Fomento Minero. 


\section{Gráfica 17}

Participación de las exportaciones mineras en el total de las exportaciones sonorenses. 1992-1995

Fuente: Gobierno del Estado de Sonora, Secretaría de Desarrollo Económico y Productividad, Dirección de Fomento Minero.

\section{Conclusiones}

El formidable crecimiento de la minería sonorense juega un papel importante en el nuevo rostro que la economía estatal ha ido dibujando en el transcurso de la década de los noventa; rostro caracterizado por un alto contenido de inversión extranjera y volcado hacia los mercados externos.

Los descalabros económicos producidos por la crisis financiera de diciembre de 1995 no se resintieron en Sonora con la virulencia que afectó a la economía mexicana, parte de la explicación la encontramos, evidentemente, en el sesgo exportador desarrollado por la estructura productiva regional y en particular por la industria minera. Sin embargo, es necesario señalar que es imposible que la minería en los tiempos actuales y pese al tremendo creci- 
miento registrado no sólo en la década presente, sino desde 1970, adquiera el peso central que tuvo en los albores del siglo. La diversificación económica actual propicia que ese papel lo jueguen otros sectores que integran mayor número de actividades productivas. La minería de hoy es, indudablemente, más moderna, como lo constatan las gigantescas inversiones realizadas desde la mexicanización de la Compañía Minera de Cananea en 1971 hasta el imparable arribo del capital foráneo que ha distinguido la década de los noventa. Sin duda, la minería actual es intensamente más moderna, globalizada y diversificada, pero también cada vez menos mexicana y menos sonorense.

Los inocultables logros en la producción minera, mostrados en el desarrollo de este ensayo, revelan también que la capacidad de esta actividad para generar nuevos empleos, es bastante limitada, el número de trabajadores dependientes de la minería se redujo durante los años que la producción, la inversión y las exportaciones mostraron los mayores incrementos; por otra parte, no considera el conjunto de efectos que se derivan: las condiciones de salud de los obreros mineros y el medio ambiente.

Por último, queremos destacar que los diferentes momentos de auge por los que ha transcurrido la minería sonorense han sido comandados más por inversionistas extranjeros y por grandes grupos económicos nacionales que por empresarios locales motivados por impulsar un desarrollo eminentemente regional. Ciertamente, la minería de fines del siglo XX se encuentra muy lejos de parecerse a los legendarios enclaves del señor Greene, y tampoco está cercana a la imagen de una actividad sobre la cual pueda descansar el desarrollo integral y futuro de la economía estatal. 


\section{Bibliografía}

Comercio Exterior Sonorense (1996), no. 65.

Contreras Montellano, Oscar (1986), La M inería en Sonora:moderniza ción industrial y fuerza detrabajo, El Colegio de Sonora, Cuadernos de Divulgación.

y Miguel Ángel Ramírez Sánchez (1988), "La nueva minería sonorense: historia reciente de una vieja industria", en José Carlos Ramírez (coord.), La Nueva Industrialización en Sonora: $d$ caso de los sectores de alta tecnología, Hermosillo, Sonora, El Colegio de Sonora.

Covarrubias Valdenebro, Alejandro (1991), "Historia y actualidad del Grupo Industrial Minera México", Revista de Estudios Sociales, no. 4, julio-diciembre.

(1991), "La industria minera y del cemento de Sonora ante el Tratado de Libre Comercio", Revista de El Colegio de Sonora, no. 3.

Gobierno del Estado de Sonora (1985), Historia General de Sonora, tomo IV, Hermosillo, Sonora,

(1996), Quinto Informe de Gobierno, Hermosillo, Sonora.

Guerrero de la Llata, Guadalupe (1997), La importancia de la inversión extranjera directa en Sonora, tesis de Licenciatura.

Historia General de Sonora, t. v, Hermosillo, Sonora.

Ramírez, José Carlos (1991), H ipótesis sobre la historia económica y demo gráfica deSonora en la era contemporánea del capital (1930-1990), Hermosillo, Sonora, Serie Cuadernos deTrabajo, El Colegio de Sonora. 
Suplemento del periódico Cambio (1997), mayo.

Trabecke Z. Karin (1996), El auge aurífero de Sonora en los noventas: facto res de competitividad y comercio exterior, tesis de licenciatura. 
